Research Article

\title{
Reaction Kinetics of Levulinic Acid Synthesis from Glucose Using Bronsted Acid Catalyst
}

\author{
Meutia Ermina Toif ${ }^{1,2}$, Muslikhin Hidayat ${ }^{2}$, R. Rochmadi'2, Arief Budiman ${ }^{2,3, *}$ \\ ${ }_{1}^{1}$ LPP Agro Nusantara, Yogyakarta, Indonesia. \\ ${ }^{2}$ Department of Chemical Engineering, Faculty of Engineering, Gadjah Mada University, Yogyakarta, \\ Indonesia. \\ ${ }_{3}^{3}$ Master Program in System Engineering, Gadjah Mada University, Yogyakarta, Indonesia.
}

Received: 30 th August 2021; Revised: 22 $2^{\text {nd }}$ September 2021; Accepted: 23rd September 2021 Available online: 25th September 2021; Published regularly: December 2021

\section{Abstract}

Glucose is one of the primary derivative products from lignocellulosic biomass, which is abundantly available. Glucose has excellent potential to be converted into valuable compounds such as ethanol, sorbitol, gluconic acid, and levulinic acid (LA). Levulinic acid is an exceptionally promising green platform chemical. It comprises two functional groups, ketone and carboxylate, acting as highly reactive electrophiles for a nucleophilic attack. Therefore, it has extensive applications, including fuel additives, raw materials for the pharmaceutical industry, and cosmetics. This study reports the reaction kinetics of LA synthesis from glucose catalyzed by hydrochloric acid (HCl), a Bronsted acid, that was carried out under a wide range of operating conditions; i.e. the temperature of $140-180{ }^{\circ} \mathrm{C}$, catalyst concentration of $0.5-1.5 \mathrm{M}$, and initial glucose concentration of $0.1-0.5 \mathrm{M}$. The highest LA yield of $48.34 \%$ was able to be obtained from an initial glucose concentration of $0.1 \mathrm{M}$ and by using $1 \mathrm{M} \mathrm{HCl}$ at $180{ }^{\circ} \mathrm{C}$. The experimental results show that the Bronsted acid-catalyzed reaction pathway consists of glucose decomposition to levoglucosan (LG), conversion of LG to 5-hydroxymethylfurfural (HMF), and rehydration of HMF to LA. The experimental data yields a good fitting by assuming a first-order reaction model.

Copyright (C 2021 by Authors, Published by BCREC Group. This is an open access article under the CC BY-SA License (https://creativecommons.org/licenses/by-sa/4.0).

Keywords: Bronsted Acid; Glucose; Kinetics; Levoglucosan; Levulinic Acid

How to Cite: M.E. Toif, M. Hidayat, R. Rochmadi, A. Budiman (2021). Reaction Kinetics of Levulinic Acid Synthesis from Glucose Using Bronsted Acid Catalyst. Bulletin of Chemical Reaction Engineering \& Catalysis, 16(4), 904915 (doi: 10.9767/bcrec.16.4.12197.904-915)

Permalink/DOI: https://doi.org/10.9767/bcrec.16.4.12197.904-915

\section{Introduction}

Until now, there has been a lot of fossilbased materials that are used in many industries. Hazardous materials emission and global warming are environmental problems from fossil-based materials [1]. On the other hand, the world fossil fuel reserves are continuously declining in quantity. A renewable raw material known as lignocellulosic biomass can instead serve as an alternative to fossil fuel in energy and chemical production.

* Corresponding Author.

Email: abudiman@ugm.ac.id (A. Budiman)
Lignocellulosic biomass is generally available from forest and agricultural residues [2]. It can reduce inorganic carbon from the environment. Moreover, the production of biomass via photosynthesis can reach 150 million tons per year [3]. Thus, the sustainable resource development goal can be potentially achieved through implementing biomass production [4]. Recently, numerous researchers have begun to focus on converting biomass into various types of material to develop more eco-friendly technology. Biomass conversion can also solve problems related to agricultural residue [5]. Furthermore, biomass as residue with low or even negative value has 
an advantage since it does not compete with food consumption demand [6].

Cellulose, hemicellulose, and lignin are the main components of lignocellulosic biomass. Each of these components can be cracked or broken down into various beneficial compounds. Cellulose is a stable polymer composed of anhydroglucose units in linear glucan chains [2]. In general, cellulose undergoes hydrolysis to produce glucose, the smallest and most abundantly available sugar unit [7]. Glucose is a C6 sugar that can react with an acid catalyst to form levulinic acid (LA) as the final product [8].

Levulinic acid, commonly known as 4oxopentanoic acid, is soluble in water and ethanol [9]. This colourless crystalline compound has a melting point of $33-37^{\circ} \mathrm{C}$, a boiling point of $245-246^{\circ} \mathrm{C}$, and a density of around $1.14 \mathrm{~g} / \mathrm{cc}$ [10]. Levulinic acid comprises two functional groups, ketone and carboxylate, acting as highly reactive electrophiles for a nucleophilic attack [11]. Because of those functional groups' high reactivity, LA can undergo esterification, oxidation-reduction, substitution, and condensation [12]. The nature of the ketone and carboxylate contained in LA makes it one of the top bio-based chemicals that can be converted into various other compounds, such as gammavalerolactone [5], 2-methyl tetrahydrofuran [13], diphenolic acid [14], and deltaaminolevulinic acid [15]. The derivatives of LA have diverse applications ranging from fuel additives to raw materials for the pharmaceutical industry and cosmetics additives [16].

The demands of LA is projected to increase with certainty from year to year. In 2013-2020, LA market demand increased significantly from 2,606.2 tons to 3,820 tons. This production was estimated to generate over 19.65 million USD with an annual growth rate of $4.8 \%$ [17]. The current LA price range (5-8 USD/kg) can be significantly lowered to $0.09-0.22 \mathrm{USD} / \mathrm{kg}$ by utilizing the low-economic value and abundant resources, such as biomass derivatives, as its raw material [18]. As production price can be lowered, the selling price of the product will consequently become cheaper, leading to the more efficient usage of LA as a precursor for other compounds.

Among various available methods for synthesizing LA, one way is to heat the C6 sugar or carbohydrates containing $\mathrm{C} 6$ sugar with a dilute mineral acid catalyst for a specific time [19]. Mineral acid catalysts usually promote a relatively higher yield of the LA product concerning their easy interaction with the reactants [5]. Regardless, the commonly used cata- lyst in the LA synthesis is Bronsted acid or Lewis acid. Levulinic acid synthesis proceeds through several stages of reactions involving several complex essential intermediate compounds, depending on the type of catalyst used.

Signoretto et al. specified a potential pathway of LA synthesis through fructose as an intermediate [20]. Glucose undergoes isomerization to fructose. From the obtained fructose, HMF is formed via cyclic or acyclic dehydration. The fructose route can be carried out when Lewis acid is used as a catalyst. Unfortunately, Lewis acid also catalyzes more byproducts such as humin [7]. Another study by Mukherjee et al. [10] explained that the C6 sugar catalyzed by Bronsted acid is initially dehydrated to form an intermediate called HMF by losing three water molecules, which subsequently undergoes rehydration to form the final products, namely LA.

The Bronsted acid catalysts are known to provide sufficient protons for reactant of hydrolysis process to LA. The study reporting the LA synthesis from cellulose and xylan shows that using Bronsted acid as the catalyst will give an effective catalytic activity to obtain the high yield of LA [21]. Another study regarding mineral acids, powerful Bronsted acids, also showed an excellent ability to convert cellulose to LA [22]. Some of the Bronsted acids are $\mathrm{HCl}$, $\mathrm{H}_{2} \mathrm{SO}_{4}$, and $\mathrm{H}_{3} \mathrm{PO}_{4}$. Hydrochloric acid is 12 times more reactive than $\mathrm{H}_{2} \mathrm{SO}_{4}$ with similar selectivity. This phenomenon occurs due to the better proton activity of $\mathrm{HCl}$. Meanwhile, another acid catalyst, $\mathrm{H}_{3} \mathrm{PO}_{4}$ is too weak for LA synthesis [23]. Hydrochloric acid is the most preferred catalyst for converting various materials into LA due to its easy recovery and separation by simple vacuum distillation [10].

Previous researchers have developed kinetic models of LA synthesis. Saeman was the first researcher to propose a kinetic model of glucose conversion into decomposition products [24]. Typically, the models proposed by researchers include the immediate reaction of glucose to HMF followed by the reaction of HMF to LA [11,25-27]. In comparison, another study mentioned that the best model for glucose hydrolysis to LA with Bronsted acid catalyst involves the route of glucose-unknown intermediate-HMF-LA [2]. This research will study LA synthesis from pure glucose, the main monosaccharide of biomass, as the starting part of our big project, LA synthesis from lignocellulosic biomass. The catalyst used in this experiment is $\mathrm{HCl}$, a Bronsted acid. To the best of writers' knowledge, no studies have quantitatively observed the unknown interme- 
diate mentioned by previous researchers in the glucose hydrolysis to LA by a Bronsted acid catalyst. Therefore, this research is aimed to reveal and quantitatively study the unknown intermediate compound in the reaction route. The effect of temperature, catalyst concentration, and initial glucose concentration on glucose conversion and LA yield is also examined. Simultaneous reactions of LA synthesis from glucose involving the unknown intermediates are modelled by the first-order reaction equation.

\section{Materials and Methods}

\subsection{Materials}

The materials used in this study were (1) LG, HMF, and LA obtained from Sigma Aldrich; (2) glucose and $37 \% \mathrm{HCl}$ obtained from Merck.

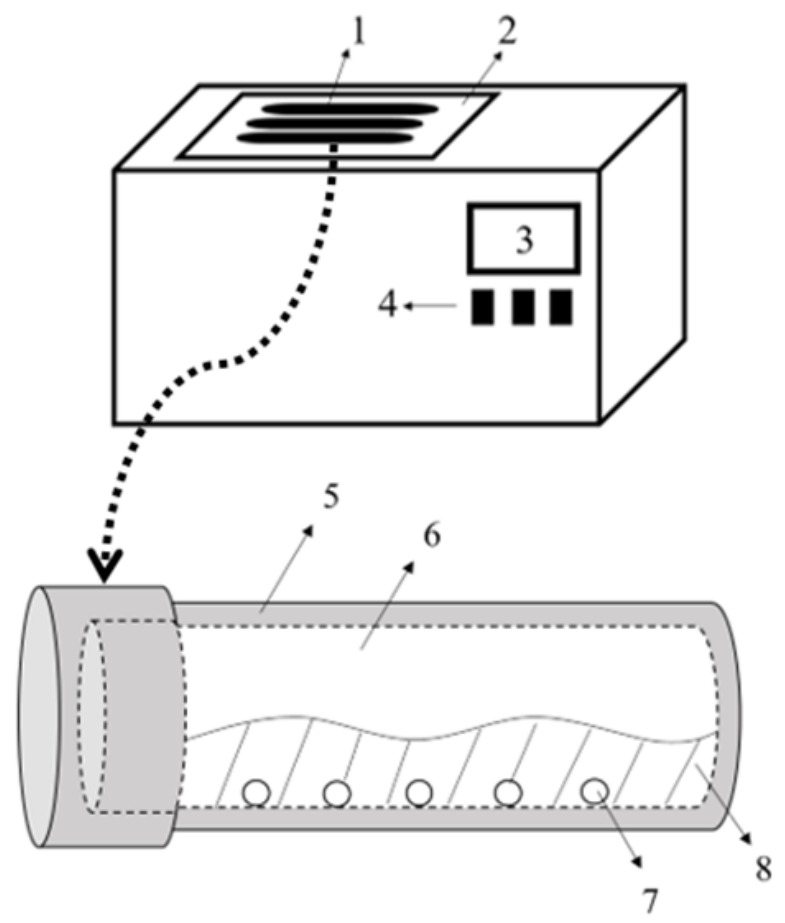

Figure 1. The scheme of the experimental setup. (1) reactor, (2) heating oil, (3) temperature indicator, (4) switch, (5) stainless steel tube, (6) glass tube, (7) stirring balls, (8) solution.

\subsection{Experimental Procedures}

The scheme of the experimental setup is demonstrated in Figure 1. The reaction was carried out in a glass tube with an inner diameter of $15 \mathrm{~mm}$ and a length of $10 \mathrm{~cm}$. The glass tube was filled with $0.1-0.5 \mathrm{M}$ glucose solution and $0.1-1.5 \mathrm{M} \mathrm{HCl}$ catalyst with a total volume of $10 \mathrm{~mL}$ in each tube. The filled glass tube was placed in a stainless-steel tube for some safety considerations. The tubes were placed in a shaking oil bath where the temperature was set at $140-180{ }^{\circ} \mathrm{C}$. After reaching a particular time, the tube was removed from the oil bath and immediately cooled until it reached room temperature. The reaction product was then separated using filter paper to obtain the filtrate (liquid phase) and the remaining solid.

Liquid sample analysis was conducted by HPLC. This analysis was used to determine the concentration of glucose, LG, HMF, and LA in the filtrate. The column used was Waters Nova-Pak C18 with a refractive index detector. The operating condition was at a temperature of $30{ }^{\circ} \mathrm{C}$. The mobile phase used was $5 \mathrm{mM}$ $\mathrm{H}_{2} \mathrm{SO}_{4}$ with a flow rate of $0.6 \mathrm{~cm}^{3} / \mathrm{min}$. The compounds' concentration was obtained using a standard curve method.

The equations used to calculate the glucose conversion $\left(X_{G}\right)$ and LA yield ( $\left.Y_{L A}\right)$ were written as follows:

$$
\begin{aligned}
& X_{G}=\frac{n_{G 0}-n_{G}}{n_{G 0}} \\
& Y_{L A}(\%)=\frac{n_{L A}}{n_{G 0}} \times 100
\end{aligned}
$$

where, $n_{G o}$ refers to the initial mole of glucose, $n_{G}$ is the mole of glucose at a particular time, and $n_{L A}$ is the mole of LA formed at a specific time.

\subsection{Modelling}

The kinetic model was developed to understand the effect of temperature, initial reactant concentration, and catalyst concentration on

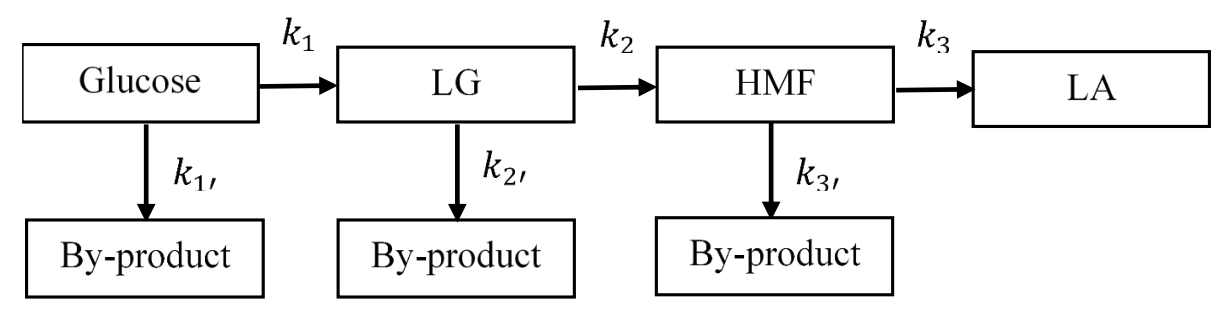

Figure 2. Reaction network of glucose conversion to LA. 
products, intermediates, and reactants' concentration profiles. The conversion of glucose using the $\mathrm{HCl}$ catalyst in this experiment is simplified in the reaction network, as shown in Figure 2.

Unlike the existing models, it was assumed that LG is an intermediate product included in the kinetic modelling. The reactions that occur in the LA synthesis from glucose were specified as follows: (1) $r_{1}$ : reaction rate of glucose to $\mathrm{LG}$ and $r_{1}$ : : reaction rate of glucose to by-products, (2) $r_{2}$ : reaction rate of $L G$ to $\mathrm{HMF}$ and $r_{2}$ : reaction rate of LG to by-products, and (3) $r_{3}$ : reaction rate of HMF to LA and $r_{3}$ ': reaction rate of HMF to by-products. The following reaction equations were used to estimate the kinetic parameters:

$$
\begin{aligned}
& r_{1}=k_{1} C_{G} \\
& r_{1}{ }^{\prime}=k_{1}^{\prime} C_{G} \\
& r_{2}=k_{2} C_{L G} \\
& r_{2}{ }^{\prime}=k_{2}{ }_{2} C_{L G} \\
& r_{3}=k_{3} C_{H M F} \\
& r_{3}{ }^{\prime}=k_{3}{ }_{3} C_{H M F} \\
& k_{i}=A_{i} \exp \left(-\frac{E_{i}}{R T}\right) \\
& \frac{d C_{G}}{d t}=-r_{1}-r_{1}{ }^{\prime} \\
& \frac{d C_{L G}}{d t}=r_{1}-r_{2}-r_{2}{ }^{\prime} \\
& \frac{d C_{H M F}}{d t}=r_{2}-r_{3}-r_{3}{ }^{\prime} \\
& \frac{d C_{L A}}{d t}=r_{3}
\end{aligned}
$$

where, $k_{i}$ is the reaction rate constant of reaction $i(1 / \mathrm{min}), A_{i}$ is the Arrhenius constant of $i$ (1/min), $E_{i}$ is the activation energy of $i(\mathrm{~kJ} / \mathrm{mol})$, $R$ is the ideal gas constant $(8.314 \mathrm{~J} /(\mathrm{mol} . \mathrm{K}))$, and $T$ is the temperature (K).

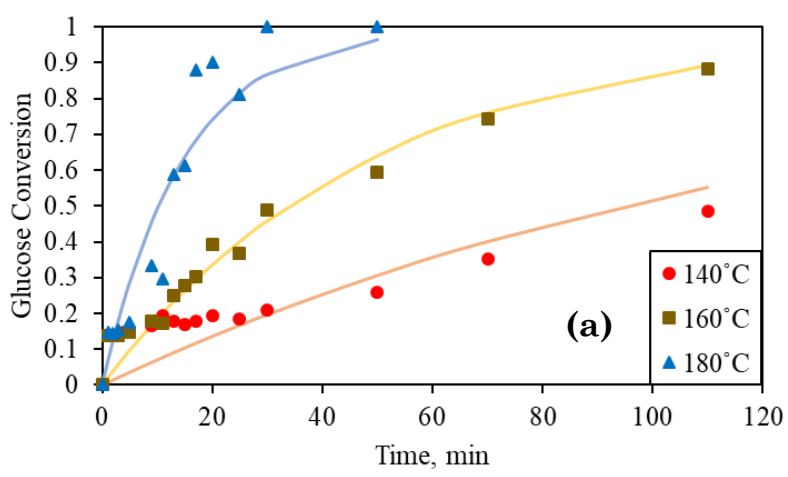

The kinetic parameters of all reactions were determined using the MATLAB software package. Estimation was done by minimizing the sum of squared of errors (SSE) between experimental data and the model results.

\section{Results and Discussion}

A total of 18 batches of experiments with various operating conditions were carried out. The studied parameters were the effect of operating conditions on glucose conversion, LA yield, and reaction kinetics values. Most experimental batches were capable of achieving up to $100 \%$ glucose conversion. The highest LA yield obtained from this experiment was $48.34 \%$ at the initial concentration of $0.1 \mathrm{M}$ glucose, by using $1 \mathrm{M} \mathrm{HCl}$, and at a temperature of $180^{\circ} \mathrm{C}$.

\subsection{The Effect of Operating Conditions}

\subsubsection{Temperature}

The effect of temperature on glucose conversion is shown in Figure 3(a). As the reaction temperature increases, the rate of glucose decomposition also increases significantly. The higher the operating temperature, the faster the glucose conversion will be. Achieving complete conversion takes only about 50 minutes for a temperature of $180{ }^{\circ} \mathrm{C}$ and about 110 minutes for $160{ }^{\circ} \mathrm{C}$. At the lowest temperature used in this experiment, $140{ }^{\circ} \mathrm{C}, 100 \%$ conversion is not achieved until the longest reaction time. This effect of temperature on glucose conversion is in line with the experiment conducted by Ma et al. [28] and Toif et al. [29].

The higher the operating temperature, the maximum LA yield is achieved faster, as demonstrated in Figure 3(b). At $140{ }^{\circ} \mathrm{C}$, the LA yield at 110 minutes is only almost $15 \%$. Meanwhile, when the temperature is raised to 160 ${ }^{\circ} \mathrm{C}$ and $180{ }^{\circ} \mathrm{C}$, the maximum yield can reach slightly above $35 \%$. Furthermore, at $180{ }^{\circ} \mathrm{C}$,

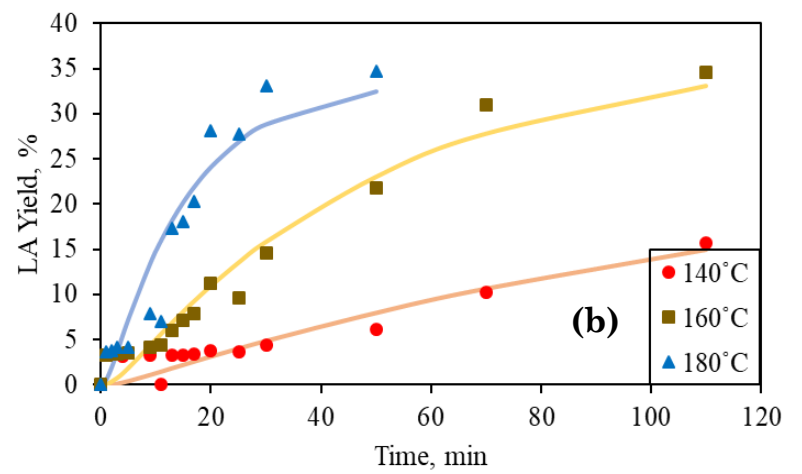

Figure 3. (a) Glucose conversion and (b) $\mathrm{LA}$ yield $\left(\mathrm{CG}_{0}=0.25 \mathrm{M} ; \mathrm{CH}=0.5 \mathrm{M}\right)$. 
the maximum yield is gained faster than at lower temperatures. The results are consistent with Shen and Wyman [30]. However, LA yield declined at a too high temperature. Chang et al. [31] stated that temperatures higher than $210{ }^{\circ} \mathrm{C}$ would cause side reactions to occur more rapidly, thus lowering the LA yield. Another study stated that LA concentrations could drop when temperatures exceed $190{ }^{\circ} \mathrm{C}$, due to further reactions [18]. It is also supported by Yan et al. [32] that LA dehydrates to unsaturated lactone at temperatures above 230 ${ }^{\circ} \mathrm{C}$.

\subsubsection{Catalyst concentration}

The effect of catalyst concentration on glucose conversion is shown in Figure 4(a). In general, complete glucose conversion is achieved faster when the catalyst concentration used is higher. At the highest catalyst concentration of 1.5 M, complete conversion is achieved in only 80 minutes. A similar result was obtained by Kupiainen et al. [2]. Otherwise, low catalyst concentration causes a lack of $\mathrm{H}^{+}$ions to hydrolyze the reactants, thus slowing down the reaction rate [32].

Figure 4(b) shows that the formation of LA is affected by the concentration of the catalyst. The maximum yield achieved at different catalyst concentrations is similar for 1 and $1.5 \mathrm{M}$ $\mathrm{HCl}$, yet the speed to achieve the maximum
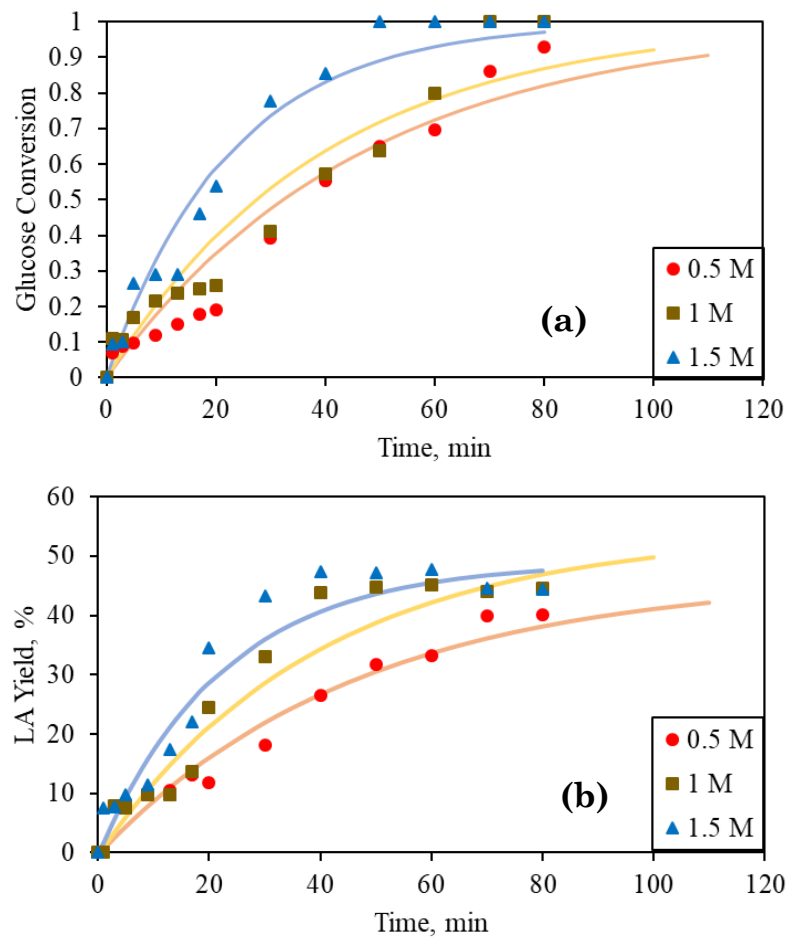

Figure 4. (a) Glucose conversion and (b) LA yield $\left(\mathrm{CG}_{0}=0.1 \mathrm{M} ; \mathrm{T}=160{ }^{\circ} \mathrm{C}\right)$. yield is slightly different. Higher catalyst concentration resulting in faster reaction time for obtaining maximum LA yield. The maximum yield of LA in the reaction carried out with the lowest catalyst concentration is reached in 110 minutes. A similar result was also obtained by Anggorowati et al. [33], which stated that the LA yield is higher with the increasing catalyst concentration for the same reaction time.

\subsubsection{Initial glucose concentration}

Another parameter affecting glucose conversion and LA yield is the initial glucose concentration demonstrated in Figure 5(a). Higher initial glucose concentration speeds up the time to achieve complete glucose conversion. Conversely, the LA yield would be lowered as the initial glucose concentrations increased, as indicated in Figure 5(b). Too high glucose concentration promotes other reactions, such as polymerization and rehydration, resulting in by-product formation [28].

In this study, the main generated byproduct was a visible dark solid. This byproduct is humin, a typical residue resulting from the LA synthesis based on the biomass and its derivatives $[5,8,34]$. The humin mainly consists of furan-type fragments with nearly $60 \%$ carbon [2]. The humin is increasingly formed as the operating temperature is too high [32], the catalyst concentration and initial
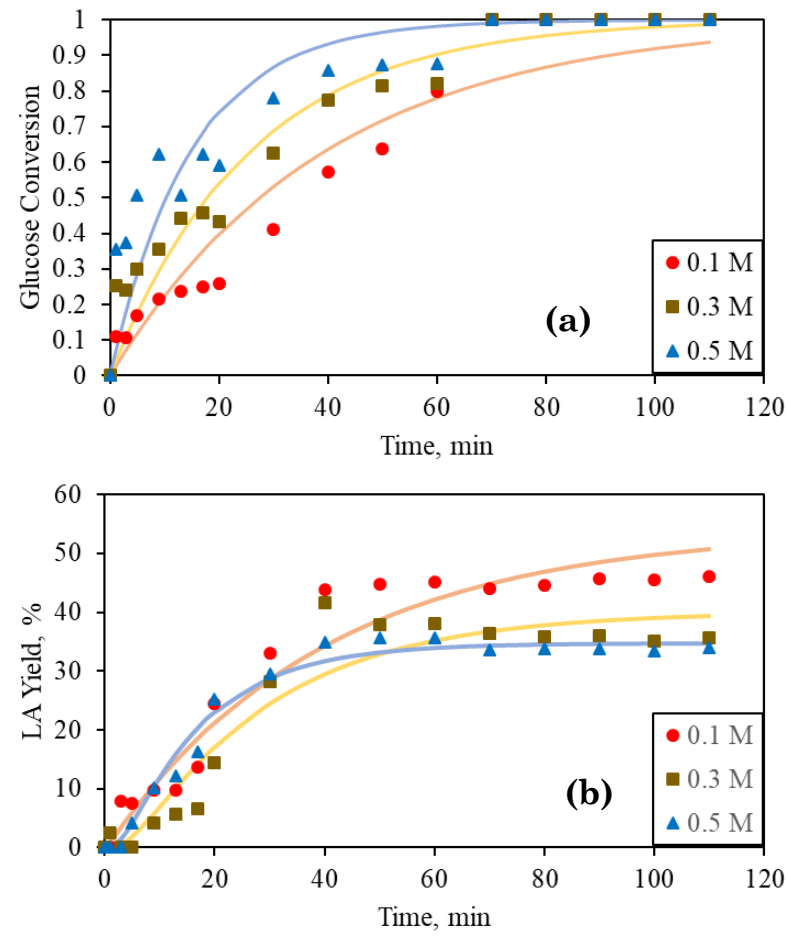

Figure 5. (a) Glucose conversion and (b) LA yield $\left(\mathrm{CH}=1 \mathrm{M} ; \mathrm{T}=160^{\circ} \mathrm{C}\right)$. 
concentration are too high [26], and the reaction time is getting longer [35]. Several other side products were also detected in the liquid phase. However, it was unable to be identified due to the limited available equipment facilities. According to Girisuta et al. [8], 1,6anhydro-beta-D-glucofuranose was observed as the reversion product, while isomaltose and gentibiose appeared due to an intermolecular condensation reaction between 2 glucose units [8].

\subsection{Kinetic Model}

In this experiment, $\mathrm{HCl}$ (a Bronsted acid) was being used. According to the HPLC analysis, the fructose reaction pathway was not detected, in contrast to the reports by Jiang et al. [36] and Feng et al. [21]. If fructose formation is promoted as an intermediate of glucose dehydration, it should have been detectable, consid-

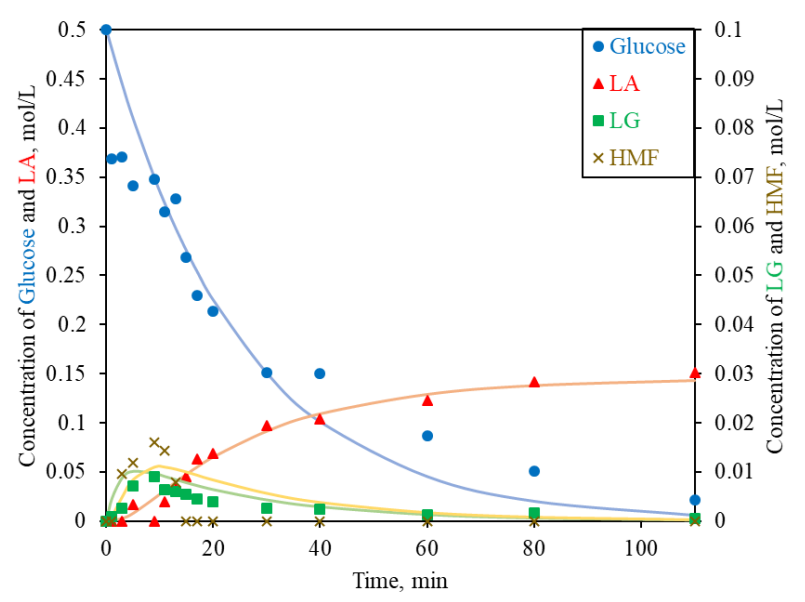

Figure 6. Typical concentration pofile of glucose hydrolysis to LA $\left(C_{\mathrm{G} 0}=0.5 \mathrm{M} ; C_{\mathrm{H}}=0.5\right.$ $\left.\mathrm{M} ; 170^{\circ} \mathrm{C}\right)$. ering the sufficient and suitable ability to analyze the fructose. The direct dehydration pathway of glucose without passing through fructose intermediate is a characteristic of the Bronsted acid-catalyzed conversion route. The isomerization of glucose to fructose cannot be catalyzed by Bronsted acid but requires Lewis acid or Bronsted base [7]. Unfortunately, Lewis acid potentially increases the formation of byproducts. Kuster and Temmink [37] studied the effect of $\mathrm{pH}$ on glucose conversion, and they observed no isomerization of glucose to fructose at $\mathrm{pH}<4.5$, as well as observed in this experiment.

According to the experimental results, LG was proven to be involved in the hydrolysis reaction of glucose to LA. Takahashi et al. [38] explained that glucose decomposes into LG, and then LG becomes an unknown degradation product. In addition, Weingarten et al. [39] reported that LG is formed from glucose dehydration, which undergoes double dehydration to HMF. Furthermore, Herbs and Janiak [40] reported that the LG route would occur when the reaction is carried out using a Bronsted acid catalyst, as was done in this study.

The essential compounds resulting from the glucose conversion were identified with HPLC, including glucose, HMF, LG, and LA. Based on Figure 6, the trend in the concentration of the compounds involved implies a consecutive reaction. The rate of glucose decomposition can be assumed to be a first-order reaction. In this model, the reaction rate is directly proportional to the concentration of each reactant. The results of the kinetic parameter estimation can be seen in Table 1.

Figure 7 demonstrates the fitted data under various operating conditions. The kinetic model provides a good fit to the experimental data

Table 1. Kinetic parameter of LA synthesis from glucose.

\begin{tabular}{lllllllll}
\hline $\mathrm{T},{ }^{\circ} \mathrm{C}$ & $C_{\mathrm{G}}, \mathrm{M}$ & $C_{\mathrm{H}}, \mathrm{M}$ & $k_{1}, \mathrm{~min}^{-1}$ & $k_{1}{ }^{\prime}, \mathrm{min}^{-1}$ & $k_{2}, \mathrm{~min}^{-1}$ & $k_{2}^{\prime}, \mathrm{min}^{-1}$ & $k_{3}, \mathrm{~min}^{-1}$ & $k_{3}{ }^{\prime}, \mathrm{min}^{-1}$ \\
\hline 140 & & & 0.00202 & 0.00530 & 0.35231 & 0.14849 & 2.03695 & 0.04028 \\
160 & 0.5 & 0.5 & 0.00762 & 0.01286 & 0.47658 & 0.21068 & 4.67840 & 0.16031 \\
180 & & & 0.02290 & 0.04490 & 0.75650 & 0.34440 & 7.15640 & 0.28920 \\
\hline & & 0.5 & 0.01003 & 0.01144 & 2.70585 & 0.47765 & 7.70919 & 0.21797 \\
& 0.1 & 1 & 0.01373 & 0.01162 & 2.84934 & 0.55666 & 9.34686 & 0.27172 \\
160 & & 1.5 & 0.02178 & 0.02274 & 4.52632 & 0.73966 & 14.8376 & 0.32124 \\
\cline { 2 - 7 } & 0.1 & & 0.01373 & 0.01162 & 2.84934 & 0.55666 & 9.34686 & 0.27172 \\
& 0.3 & 1 & 0.01551 & 0.02324 & 0.55002 & 0.60275 & 0.27975 & 0.36418 \\
& 0.5 & & 0.02335 & 0.04398 & 0.84105 & 0.65806 & 0.40604 & 0.45398 \\
\hline$E$, & & & 94.4637 & 82.7891 & 29.5995 & 32.6366 & 49.0717 & 49.3029 \\
$\mathrm{~kJ} / \mathrm{mol}$ & & & & & & & &
\end{tabular}


$\mathrm{CG}_{0} 0.5 \mathrm{M} \mathrm{C}_{\mathrm{H}} 0.5 \mathrm{M} 150^{\circ} \mathrm{C}$

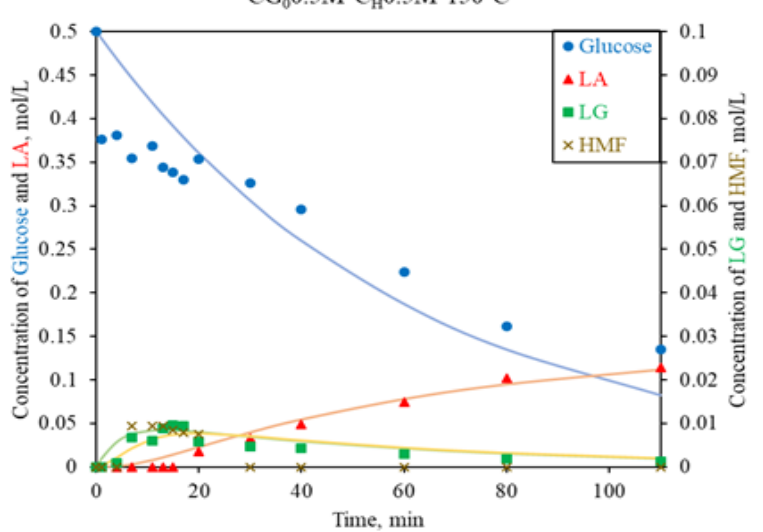

$\mathrm{CG}_{0} 0.25 \mathrm{M} \mathrm{C}_{\mathrm{H}} 0.5 \mathrm{M} 140^{\circ} \mathrm{C}$

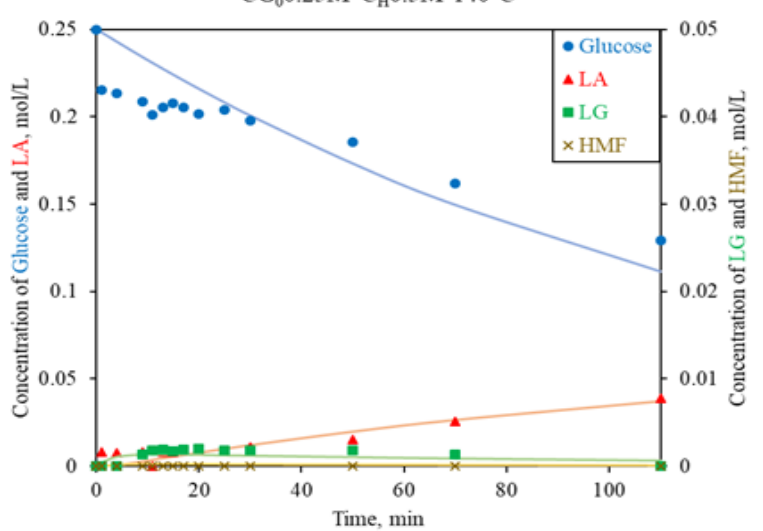

$\mathrm{CG}_{0} 0.1 \mathrm{M} \mathrm{C}_{\mathrm{H}} 1 \mathrm{M} 160^{\circ} \mathrm{C}$

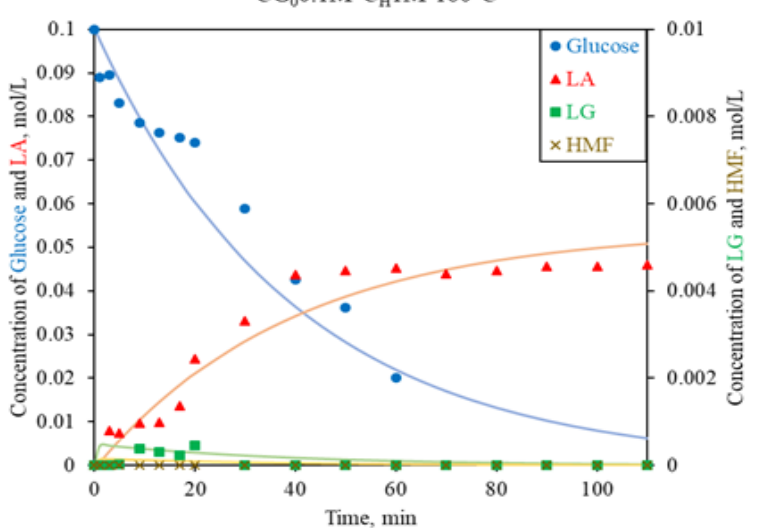

$\mathrm{CG}_{0} 0.3 \mathrm{M} \mathrm{C} \mathrm{H}_{\mathrm{H}} 1 \mathrm{M} 160^{\circ} \mathrm{C}$

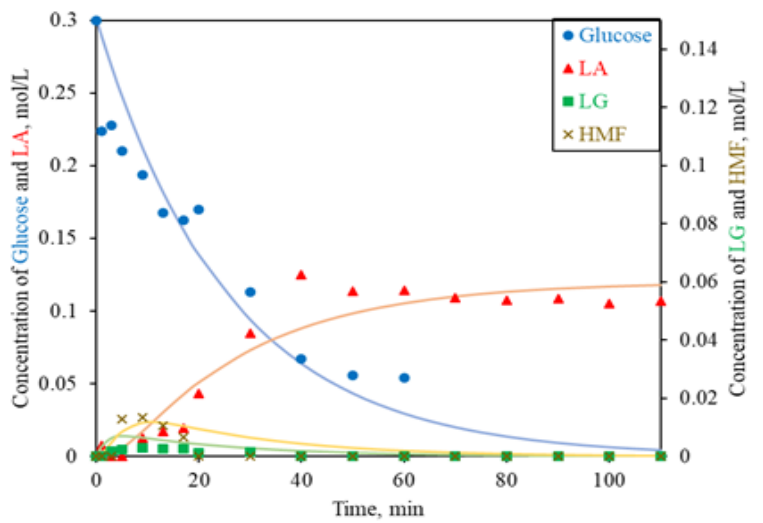

$\mathrm{CG}_{0} 0.5 \mathrm{M} \mathrm{C}_{\mathrm{H}} 0.5 \mathrm{M} 160^{\circ} \mathrm{C}$

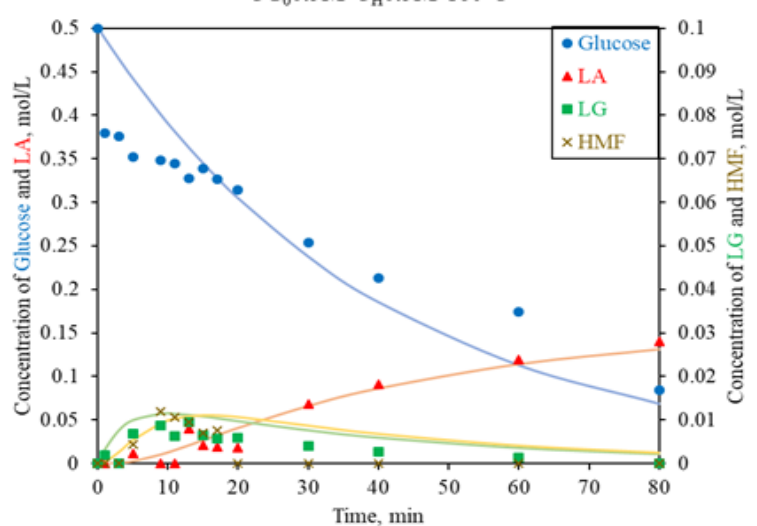

$\mathrm{CG}_{0} 0.25 \mathrm{M} \mathrm{C}_{\mathrm{H}} 0.5 \mathrm{M} 160^{\circ} \mathrm{C}$

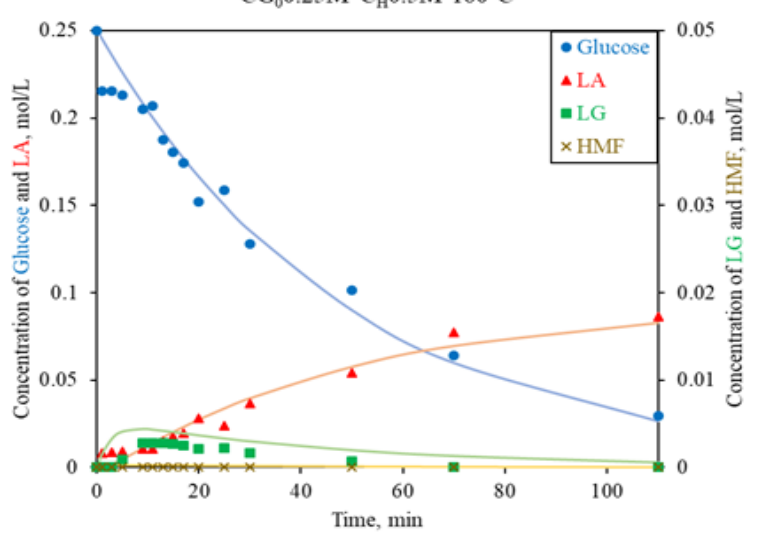

$\mathrm{CG}_{0} 0.1 \mathrm{M} \mathrm{C}_{\mathrm{H}} 1.5 \mathrm{M} 180^{\circ} \mathrm{C}$

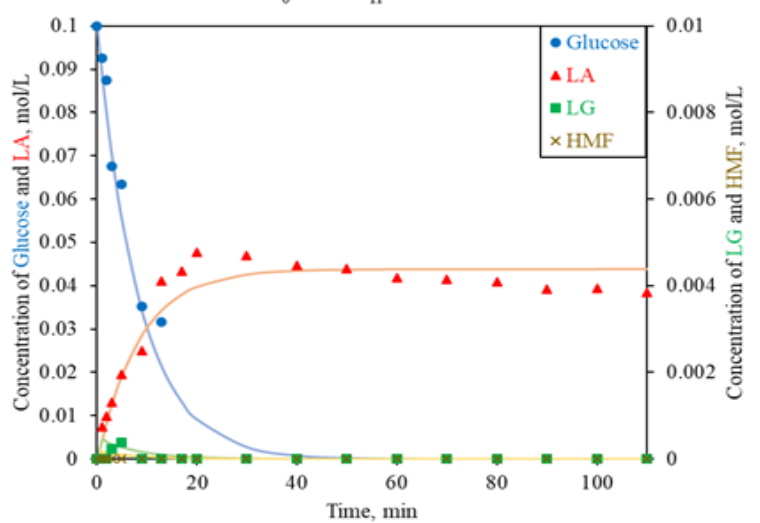

$\mathrm{CG}_{0} 0.5 \mathrm{M} \mathrm{C}_{\mathrm{H}} 1 \mathrm{M} 180^{\circ} \mathrm{C}$

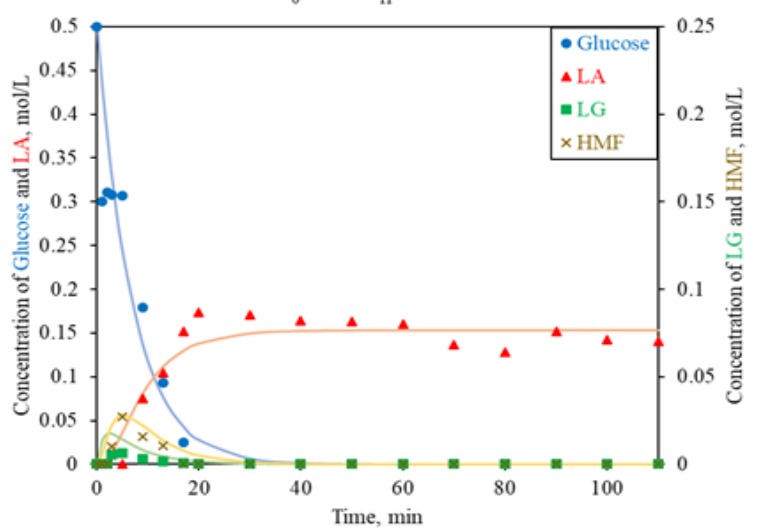

Figure 7. Model fitting at various operating conditions. 
and over a wide range of reaction conditions. It can be seen that the assumption of first-order reactions is suitable for LA synthesis reaction from glucose involving LG and HMF as the intermediates.

Glucose conversion can reach $100 \%$, but the maximum LA yield is only $48.34 \%$. It indicates that there are other reaction products derived from the reactants and intermediates besides LA. Levoglucosan and HMF were observed as intermediates in the reaction sequence. The concentrations of LG and HMF are generally small compared to both the LA product concentration and the initial glucose concentration. These observations indicate that LA product formation is much faster than the conversion of glucose into intermediates, which can be seen from the value of $k$ in Table 1 .

The reaction temperature was varied to determine its effect on the kinetic parameters. The temperature has a strong influence on glucose decomposition, seen from its $k$ value in Table 1 . The higher the temperature, the higher the value of $\mathrm{k}$ in all reactions. It simply means that the reaction run faster when the temperature is set to be higher. However, the values of $k_{1}^{\prime}, k_{2}^{\prime}$, and $k_{3}^{\prime}$ are also higher, which indicates that the reaction into by-products occurs more rapidly when high temperature is applied. The highest activation energy value is $E_{1}$ (glucose decomposition into LG). Therefore, the decomposition of glucose into LG is the most sensitive reaction among those reaction sequences.

It can also be seen that the decomposition of glucose increases with the increasing acid concentration. The $k$ values for the primary reaction are consistently increasing with higher acid concentration. However, all $k$ values for side reactions had a similar trend. The primary reaction goes faster as the side reaction rate increases. It is identical to the result from Chang et al. [11]. Slightly opposed to the results obtained in this experiment, Xiang et al. [41] stated that acid concentration has minimal effect on the overall decomposition rate. Tarabanko et al. [23] provides a clearer explanation, where the kinetics of LA formation from glucose at the medium temperature is slightly affected by the acid concentration. Nevertheless, the LA formation rate increased markedly with the increasing acid concentration when the reaction is carried out at elevated temperatures.

Glucose decomposition to LA can be done using: (1) concentrated acid at low temperature or (2) dilute acid at high temperature. Both of these conditions can produce a high yield of LA. The condition of concentrated acid and low temperature drives higher amounts of acid con- sumption and the longer reaction time required. The losses in terms of equipment corrosion and difficulty in acid recovery occurs when applied on an industrial scale. Conversely, the acid consumption and reaction time can be significantly reduced at higher temperature conditions. It is also helpful in reducing side products [42]. Therefore, hydrolysis at high temperatures in dilute acid is considered better from an economic point of view.

The initial glucose concentration as a reactant also influences the reaction kinetics. When the initial glucose concentration used is too low, less than 0.3 M, HMF is undetectable and the calculation based on the reaction kinetic model resulted in a very small value. The values of $k_{3}$ and $k_{2}$ were also considered very large, compared to the values at the higher initial glucose concentration conditions. It shows that too low initial glucose concentration induced a rapid decomposition rate of HMF. In general, the higher the initial glucose concentration, the higher the value of the reaction rate constant, as shown in Table 1.

\subsection{Comparison with Previous Kinetic Models}

Based on the experimental results, the glucose hydrolysis reaction is consistent with the first-order reaction model. Similar trends have also been reported by previous researchers [2,8,11,43]. Chang et al. [11] and Kupiainen et al. [2] modified the Arrhenius equation in the model. Kupiainen et al. also involved the formic acid dissociation constant in calculating the hydrogen ion concentration [2]. In contrast to the other researchers, Girisuta et al. [8] conducted data modelling using the power-law approach, where each compound's concentration and the acid catalyst had different order values [8]. The Arrhenius equation was modified to determine the effect of temperature on the rate constant of the reaction. In addition, the catalytic effect of sulfuric acid is also included in the model by involving the dissociation constant.

Table 2 summarizes the comparison of reaction rate constants and activation energy values between this study and previous studies which performed LA synthesis catalyzed by strong acid [8,11], weak acid [2], and solid catalyst [43]. A study designed a kinetic model with the side reactions produced from each compound [8], and the others stated that the side products were only produced by certain compounds [2,11,43]. Thus, Kupiainen et al. added an undefined intermediate compound to the kinetic model called I [2]. 


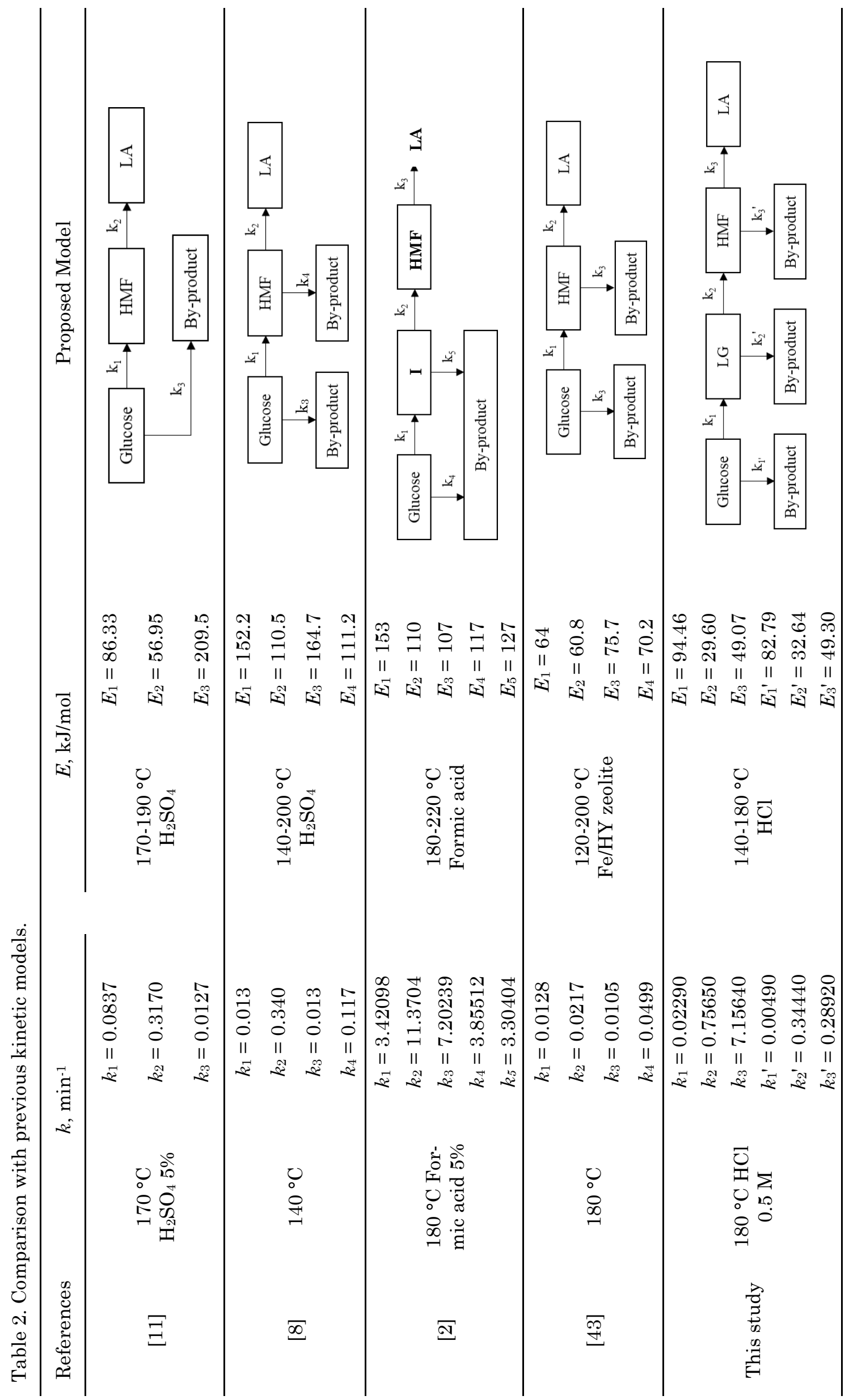


The value of the reaction rate constant obtained from this study is not exactly the same as the reference but is still considered to be within the range due to the different reaction conditions. The literatures report that the activation energy value of glucose conversion is in the range of $64-154 \mathrm{~kJ} / \mathrm{mol}[2,8,11,43]$. This study resulted in the glucose conversion activation energy value of $94.46 \mathrm{~kJ} / \mathrm{mol}$, which is within this range. Kupiainen et al. reported that the activation energy for HMF formation was $110 \mathrm{~kJ} / \mathrm{mol}$ [2], while this study obtained an activation energy value of HMF formation from $\mathrm{LG}$ of $29.60 \mathrm{~kJ} / \mathrm{mol}$. The significant value difference is due to the different catalysts and reaction models used. Next, the activation energy of LA formation from HMF stated in several previous studies ranged from 56.95-110.5 $\mathrm{kJ} / \mathrm{mol}[2,8,11,43]$. However, this study resulted in a slightly smaller value of activation energy than the previously reported range, 49.07 $\mathrm{kJ} / \mathrm{mol}$.

\section{Conclusions}

Glucose, the primary monosaccharide from lignocellulosic biomass, has been proven to be convertible to LA. The unknown intermediate involved in the reaction when using a Bronsted acid $(\mathrm{HCl})$ catalyst is LG. The concentration of LG under various operating conditions is relatively very low because the decomposition rate is much faster than the formation rate. Glucose reaction to LA is influenced by temperature, catalyst concentration, and initial glucose concentration. The higher the temperature and the catalyst concentration used, the less time to achieve full glucose conversion and maximum LA yield. On the contrary, a lower initial glucose concentration increases the LA yield. The highest LA yield successfully obtained in this experiment was $48.34 \%$ at $0.1 \mathrm{M}$ initial glucose concentration, $1 \mathrm{M} \mathrm{HCl}$, and temperature of $180^{\circ} \mathrm{C}$. The first-order reaction model involving LG in the reaction pathway gives good fitting results to the experimental data.

\section{Acknowledgements}

The authors are grateful to PMDSU (Master to Doctorate Education for Superior Scholar, Ministry of Education and Culture, Republic of Indonesia) for the financial support.

\section{References}

[1] Daorattanachai, P., Namuangruk, S., Viriyaempikul, N., Laosiripojana, N. (2012). 5Hydroxymethylfurfural Production from Sugars and Cellulose in Acid- and Base-catalyzed Conditions Under Hot Compressed Water. Journal of Industrial and Engineering Chemistry, 18, 1893-1901. D O I : 10.1016/j.jiec.2012.04.019.

[2] Kupiainen, L., Ahola, J., Tanskanen, J. (2011). Kinetics of Glucose Decomposition in Formic Acid. Chemical Engineering Research and Design, 89, 2706-2713. DOI: 10.1016/j.cherd.2011.06.005.

[3] Corma Canos, A., Iborra, S., Velty, A. (2007). Chemical Routes for the Transformation of Biomass into Chemicals. Chemical Reviews, 107, 2411-2502. DOI: 10.1021/cr050989d.

[4] Liu, C., Lu, X., Yu, Z., Xiong, J., Bai, H., Zhang, R. (2020). Production of Levulinic Acid from Cellulose and Cellulosic Biomass in Different Catalytic Systems. Catalysts, 10, 122. DOI: 10.3390/catal10091006.

[5] Yan, K., Jarvis, C., Gu, J., Yan, Y. (2015). Production and Catalytic Transformation of Levulinic Acid: A Platform for Speciality Chemicals and Fuels. Renewable and Sustainable Energy Reviews, 51, 986-997. DOI: 10.1016/j.rser.2015.07.021.

[6] Galletti, A.M.R., Antonetti, C., De Luise, V., Licursi, D., o Di Nasso, N.N. (2012). Levulinic Acid Production from Waste Biomass. Bioresources , 7, 1824-1835. DOI: 10.15376/biores.7.2.1824-1835

[7] Boonyakarn, T., Wataniyakul, P., Boonnoun, P., Quitain, A.T., Kida, T., Sasaki, M., Laosiripojana, N., Jongsomit, B., Shotipruk, A. (2019). Enhanced Levulinic Acid Production from Cellulose by Combined Brønsted Hydrothermal Carbon and Lewis Acid Catalysts. Industrial and Engineering Chemistry Research, 58, 2697-2703. DOI: 10.1021/acs.iecr.8b05332.

[8] Girisuta, B., Janssen, L.P.B.M., Heeres, H.J. (2006). A Kinetic Study on the Conversion of Glucose to Levulinic Acid. Chemical Engineering Research and Design, 84, 339-349. DOI: $10.1205 /$ cherd05038.

[9] Bozell J.J., Petersen, G.R. (2010). Technology Development for The Production of Biobased Products from Biorefinery Carbohydratesthe US Department of Energy's 'Top 10' Revisited. Green Chemistry, 12, 539-555. DOI: 10.1039/b922014c. 
[10] Mukherjee, A., Dumont, M.J., Raghavan, V. (2015). Sustainable Production of Hydroxymethylfurfural and Levulinic Acid: Challenges and Opportunities. Biomass Bioenergy, $72, \quad 143-183$. D O I : 10.1016/j.biombioe.2014.11.007.

[11] Chang, C., Ma, X., Cen, P. (2006). Kinetics of Levulinic Acid Formation from Glucose Decomposition at High Temperature. Chinese Journal of Chemical Engineering, 14, 708712. DOI: 10.1016/S1004-9541(06)60139-0.

[12] Maiti, S., Gallastegui, G., Suresh, G., Pachapur, V.L., Brar, S.K., Le Bihan, Y., Drogui, P., Buelna, G., Verma, M., Galvez-Cloutier, R. (2018). Microwave-assisted One-Pot Conversion of Agro-Industrial Wastes into Levulinic Acid: An Alternate Approach. Bioresource Technology, 265, 471-479. DOI: 10.1016/j.biortech.2018.06.012.

[13] Bozell, J.J., Moens, L., Elliott, D.C., Wang, Y., Neuenscwander, G.G., Fitzpatrick, S.W., Bilski, R.J., Jarnefeld, J.L. (2000). Production of Levulinic Acid and Use as A Platform Chemical for Derived Products. Resources, Conservation and Recycling, 28, 227-239. DOI: 10.1016/S0921-3449(99)00047-6.

[14] Guo, Y., Clark, J.H. (2007). The Synthesis of Diphenolic Acid Using The Periodic Mesoporous H3 PW12O40-silica Composite Catalysed Reaction of Levulinic Acid. Green Chemistry, 9, 839-841. DOI: 10.1039/b702739g.

[15] Ha, H., Lee, S., Ha, Y., Park, J. (1994). An International Journal for Rapid Communication of Synthetic Organic Chemistry Selective Bromination of Ketones. A Convenient Synthesis of 5-Aminolevulinic Acid. Synthetic Communications, 24, 2557-2562. DOI: $10.1080 / 00397919408010567$.

[16] Badgujar, K.C., Wilson, L.D., Bhanage, B.M. (2019). Recent Advances for Sustainable Production of Levulinic Acid in Ionic Liquids from Biomass: Current Scenario, Opportunities and Challenges. Renewable and Sustainable Energy Reviews, 102, 266-284. DOI: 10.1016/j.rser.2018.12.007.

[17] Grand View Research (2014). Citing Internet $\begin{array}{llllllllll}\mathrm{s} & \mathrm{o} & \mathrm{u} & \mathrm{r} & \mathrm{c} & \mathrm{e} & \mathrm{s} & \mathrm{U} & \mathrm{R} & \mathrm{L}\end{array}$ https://www.grandviewresearch.com/pressrelease/global-levulinic-acid-market.

[18] Kang, S., Fu, J., Zhang, G. (2017). From Lignocellulosic Biomass to Levulinic Acid: A Review on Acid-catalyzed Hydrolysis. Renewable and Sustainable Energy Reviews, 94, 340362. DOI: 10.1016/j.rser.2018.06.016.

[19] Weingarten, R., Cho, J., Xing, R., Jr, W.C.C., Huber, J.W. (2012). Kinetics and Reaction Engineering of Levulinic Acid Production from Aqueous Glucose Solutions. ChemSusChem, 5, 1280-1290. DOI : $10.1002 /$ cssc. 201100717
[20] Signoretto, M., Taghavi, S., Ghedini, E., Menegazo, F. (2019). Catalytic Production of Levulinic Acid (LA) from Actual Biomass. Molecules, 24, 1-20. DO I : 10.3390/molecules24152760.

[21] Feng, J., Tong, L., Xu, Y., Jiang, J., Hse, C., Yang, Z. (2020). Synchronous Conversion of Lignocellulosic Polysaccharides to Levulinic Acid with Synergic Bifunctional Catalysts in a Biphasic Cosolvent System. Industrial Crops and Products, 145, 1-9. DOI: 10.1016/j.indcrop.2019.112084.

[22] Deng, W., Zhang, Q., Wang, Y. (2015). Catalytic Transformations of Cellulose and Its Derived Carbohydrates into 5hydroxymethylfurfural, Levulinic Acid, and Lactic Acid. Science China Chemistry, 58, 2946. DOI: $10.1007 / \mathrm{s} 11426-014-5283-8$.

[23] Tarabanko, V.E., Chernyak, M.Y., Aralova, S.V., Kuznetsov, B.N. (2002). Kinetics of Levulinic Acid Formation from Carbohydrates at Moderate Temperatures. Reaction Kinetics and Catalysis Letters, 75, 117-126. DOI: 10.1023/A:1014857703817.

[24] Saeman, S. (1945). Hydrolysis of Cellulose and Decomposition of Sugars in Dilute Acid at High Temperature. Industrial and Engineering Chemistry, 37, 43-52. DOI: 10.1021/ie50421a009.

[25] Cha, J.Y., Hanna, M.A. (2002). Levulinic Acid Production Based on Extrusion and Pressurized Batch Reaction. Industrial Crops and Products, 16, 109-118. DOI: 10.1016/S09266690(02)00033-X.

[26] Zhou, C., Zhao, J., Elgasim, A., Yagoub, A., Ma, H. (2017). Conversion of Glucose into 5hydroxymethylfurfural in Different Solvents and Catalysts: Reaction Kinetics and Mechanism. Egyptian Journal of Petroleum, 26, 477-487. DOI: 10.1016/j.ejpe.2016.07.005.

[27] Jeong, G., Kim, S. (2020). Bioresource Technology Valorization of Thermochemical Conversion of Lipid-extracted Microalgae to Levulinic Acid. Bioresource Technology, 313, 17. DOI: 10.1016/j.biortech.2020.123684.

[28] Ma, Y., Wang, L., Li, H., Wang, T., Zhang, R. (2018). Selective Dehydration of Glucose into 5 -Hydroxymethylfurfural by Ionic LiquidZrOCl2 in Isopropanol. Catalysts, 8, 30-34. DOI: $10.3390 /$ catal 8100467.

[29] Toif, M.E., Hidayat, M., Rochmadi, R., Budiman, A. (2020). Glucose to Levulinic Acid, a Versatile Building Block Chemical. AIP Conference Proceedings, 2296, 1-6. DOI: 10.1063/5.0030451. 
[30] Shen, J., Wyman, C.E. (2011). Hydrochloric Acid-Catalyzed Levulinic Acid Formation from Cellulose: Data and Kinetic Model to Maximize Yields. American Institute of Chemical Engineers, 58, 236-246. DOI: 10.1002/aic. 12556

[31] Chang, C., Cen, P., Ma, X.. (2007) Levulinic Acid Production from Wheat Straw. Bioresource Technology, 98, 1448-1453. DOI: 10.1016/j.biortech.2006.03.031.

[32] Yan, L., Yang, N., Pang, H., Liao, B. (2008). Production of Levulinic Acid from Bagasse and Paddy Straw by Liquefaction in the Presence of Hydrochloride Acid. Clean, 36, 158163. DOI: $10.1002 /$ clen.200700100.

[33] Anggorowati, H., Jamilatun, S., Cahyono, R.B., Budiman, A. Effect of Hydrochloric Acid Concentration on the Conversion of Sugarcane Bagasse to Levulinic Acid. IOP Conference Series: Materials Science Engineering, $299, \quad 1-6$. DOI: $10.1088 / 1757$ 899X/299/1/012092.

[34] Szabolcs, A., Molnar, M., Dibo, G., Mika, L.T. (2013). Microwave-assisted Conversion of Carbohydrates to Levulinic Acid: An Essential Step in Biomass Conversion. Green Chemistry, 15, 439-445. DOI: 10.1039/c2gc36682g.

[35] Fachri, B.A., Abdilla, R.M., van de Bovenkamp, H.H., Rasrendra, C.B., Heeres, H.J. (2015). Experimental and Kinetic Modeling Studies on the Sulfuric Acid Catalyzed Conversion of D-Fructose to 5Hydroxymethylfurfural and Levulinic Acid in Water. Sustainable Chemistry and Engineering, $3, \quad 3024-3034$. D O I : 10.1021/acssuschemeng.5b00023.

[36] Jiang Y., Yang, L., Bohn, C.M., Li, G., Han, D., Mosier, N.S., Miller, J.T., Kenttamaa, H.I., Abu-Omar, M.M. (2015). Speciation and Kinetic Study of Iron Promoted Sugar Conversion to 5-Hydroxymethylfurfural (HMF) and Levulinic Acid (LA). Organic Chemistry Frontiers, 2, 1388-1396. DOI: 10.1039/C5QO00194C.
[37] Kuster, B.F.M., Temmink, H.M.G. (1977). The Influence of $\mathrm{pH}$ and Weak Acid Anions on The Dehydration of D-Fructose. Carbohydrate Research, 54, 185-191. DOI: 10.1016/S0008-6215(00)84808-9.

[38] Takahashi, K., Satoh, H., Satoh, T., Kakuchi, T., Miura, M., Sasaki, A., Sasaki, M., Kaga, H. (2009). Formation Kinetics of Levoglucosan from Glucose in High Temperature Water. Chemical Engineering Journal, 153, 170174. DOI: 10.1016/j.cej.2009.06.027.

[39] Weingarten, R., Rodriguez-beuerman, A., Cao, F., Luterbacher, J.S., Alonso, M., Dumesic, J.A., Huber, G.W. (2014). Selective Conversion of Cellulose to Hydroxymethylfurfural in Polar Aprotic Solvents. ChemCatChem, 6, 2229-2234. DOI: 10.1002/cctc.201402299.

[40] Herbst A., Janiak, C. (2016). Selective Glucose Conversion to 5-Hydroxymethylfurfural (5-HMF) instead of Levulinic Acid with MIL101CrMOF-derivatives. New Journal of Chemistry, 40, 7958-7967. DOI: 10.1039/C6NJ01399F.

[41] Xiang, Q., Lee, Y.Y., Torget, R.W. (2004). Kinetics of Glucose Decomposition During Dilute-Acid Hydrolysis of Lignocellulosic Biomass. Applied Biochemistry and Biotechnology, 113, 1127-1138. DOI: 10.1007/978-159259-837-3_91.

[42] Carlson, L.J. (1962). Process for The Manufacture of Levulinic Acid. US Patent, 3065263

[43] Ramli, N.A.S., Amin, N.A.S. (2016). Kinetic Study of Glucose Conversion to Levulinic Acid over Fe/HY Zeolite Catalyst. Chemical Engineering Journal, 283, 150-159. DOI: 10.1016/j.cej.2015.07.044. 